Birlesik Dünya Arastırma

BD-CENTER

Innavasyan ve Yayınellik Merkezi

\section{Global Journal of Arts Education}

Volume 11, Issue 1, (2021) 48 - 56

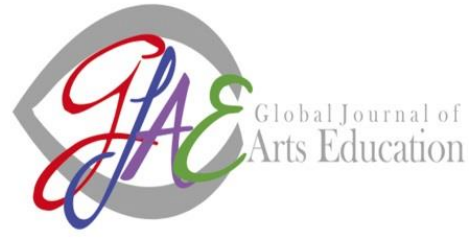

www.gjae.eu

\title{
A contemporary completion attempts in traditional texture
}

\author{
Cansu Saçan Bombar ${ }^{*}$, Dokuz Eylül University, Faculty of Architecture, Department of Architecture, Turkey \\ Hümeyra Birol ${ }^{\text {b }}$, Dokuz Eylul University, Faculty of Architecture Department of Architecture, Turkey, \\ Feyzal Avcı Özkaban ' : Dokuz Eylul University Faculty of Architecture, Department of Architecture, Turkey,
}

\section{Suggested Citation:}

Bombar, C. S., Birol, H. \& Özkaban, F. A. (2021). A contemporary completion attempts in traditional texture. Global Journal of Arts Education. 11(1), 24 -23. https://doi.org/10.18844/gjae.v11i1.5724

Received from December 15, 2020; revised from January 18, 2021; accepted from February 05, 2021.

Selection and peer review under responsibility of Prof. Dr. Ayse Cakir Ilhan, Ankara University, Turkey.

${ }^{\circ} 2021$ Birlesik Dunya Yenilik Arastirma ve Yayincilik Merkezi. All rights reserved.

\begin{abstract}
Traditional settlements are formed by the mutual interaction of the culture, technology and the geographical inputs of the physical environment, which transform over time and mature with the intertwining and overlapping of different cultural productions in processes spanning centuries. These inputs, which are described as tangible and intangible data, create the architectural characteristics of the settlements by shaping the architectural structures and the way in which these structures are associated with each other and the characteristics of that place. Today, two types of intervention needs come to the forefront, namely maintenance-repair and new construction activities in existing gaps, in traditional tissues that are faced with conservation problems due to the globalising life culture, current needs of modern life and accelerated technological development. The interventions to be carried out in this direction carry various risks and possibilities in terms of preserving and maintaining the architectural identity of traditional settlements. Based on the above query, this study focuses on a design experiment in Birgi settlement, which stands out as an important cultural tourism destination besides its traditional and rural characteristics. The study, carried out within the scope of DEU's Department of Architecture Department Restoration Master's Programme, 2018-2019 Spring Semester ARC5144 Restoration Project and Environmental Analysis course, conveys an experience on the completion of a local housing structure that has lost its building integrity with a modern approach, while at the same time, continuing, integrating with the architectural characteristics of the settlement, using today's technological possibilities, opens the question of belonging to the present.
\end{abstract}

Keywords: Traditional architecture, contemporary completion, sustainability.

\footnotetext{
" ADDRESS FOR CORRESPONDENCE: Cansu Saçan Bombar, Dokuz Eylül University, Faculty of Architecture, Department of Architecture, Turkey
}

E-mail address: mim.cansusacan@gmail.com 


\section{Introduction}

Traditional settlements are formed in a process where intangible data such as daily needs created by local life, people's habits, traditions, forms of association, belief systems and concrete data such as the natural characteristics of the region, the production dynamics of the region and the technologies of the period are intertwined. The building scale, form, material culture, space and façade setup shaped by these inputs reveal the architectural characteristics of traditional settlements. Another important input in shaping the architectural characteristics is the development and transformation that take place over time. In the period when traditional life continued, the productions carried out with local masters and materials created a natural continuity in terms of architectural characteristics. Today's globalised life culture, the current needs of modern life and the accelerating technological development carry risks in terms of preserving and sustaining the architectural characteristics. These risks, in addition to the loss of the original architectural qualities of traditional settlements, also damage the relationships that users and societies establish with that place. In this context, contemporary conservation discipline advocates the need to examine the concrete and intangible inputs that make up the architectural characteristics from a holistic perspective and to evaluate the conservation intervention not in terms of structure but in tissue scale.

Another focus of the current conservation debate is sustainable conservation. The sustainability phenomenon, which stands out in the preservation of traditional textures, refers to the search for continuity between yesterday, today and tomorrow, and instead of producing imitations of the historical structures existing in the texture, it is evaluated in accordance with the dynamic course of life, by evaluating the traditional productions of that place in accordance with the current needs and using today's technologies when necessary, adopting the interventions to be carried out. With this view, sustainability can be defined as establishing the link between the teachings of the past and the present and the future (Birol Akkurt, 2010).

In traditional settlements, in addition to wear due to natural factors such as disasters and meteorological events, protection interventions come to the fore due to reasons such as loss of users, inability to respond to current needs and changing living conditions. While some of these interventions are about improving or expanding traditional buildings with simple or substantial repairs, some of them require the completion of the tissue in the normal course of life and the production of new structures. However, while the boundaries of maintenance-repair activities to be carried out in traditional buildings are defined by the principles of protection and relevant legislation, the principles and boundaries for the production of new buildings are unclear.

Another important input in the construction of physical interventions in traditional settlements as intricate areas where tangible and intangible values are integrated, with a view that is compatible with the place, is the professional approach of the designer as the actor conducting the intervention. These areas, which have location-specific features and are expected to be maintained with an approach that reflects the day, should be planned and implemented by experts. With the transfer of Karakul (2009), these experts should be aware that their applications will be 'the last layer of the evolution of historical urban textures'. However, it is often seen that the design quality is not prioritised due to the gaps in the legislation and the socio-economic conditions of the users, and even the property owners carry out individual construction activities. In addition, due to the uncertainty of the intervention framework, there are two approaches that are frequently followed depending on the information and interpretation of the actor conducting the intervention. Both approaches, which we can define productions that replicate local architecture and do not connect with local architecture, contain risks and possibilities. At first glance, the approaches that adopt the production of copies of local architecture appear as constructions that integrate with the settlement and maintain the architectural characteristics of the 
settlement. It bears the risk of uniformity in the tissue, destroying the uniqueness value and ignoring the period it belongs to. Although approaches that do not connect with local architecture and adopt contrary productions are positive in terms of reflecting the knowledge, taste and technologies of the period in which they were built, they carry a significant risk of weakening the visual integrity and local characteristics of the existing texture. In this direction, it seems inevitable to produce an alternative approach that takes into account the possibilities and risks of the two approaches in the production of new structures to be carried out in traditional textures (Birol Akkurt, Ozkaban \& Dokgoz, 2016; Semes, 2007). With this view, it becomes important to investigate the design approaches of the place and the day, by taking references from the original characteristics of the settlement and integrating these references with the current design approach, information and construction technologies.

Based on the above query, this study focuses on a design experiment in Birgi settlement, which stands out as an important cultural tourism destination besides its traditional and rural characteristics. The study, carried out within the scope of DEU's Department of Architecture, Restoration Master's Programme, 2018-2019 Spring semester ARC5144 Restoration Project and Environmental Analysis course, conveys an experience on the completion of a local housing structure that has lost its structural integrity with a modern approach, and at the same time it opens up the questions of continuing its spirit, integrating with the architectural characteristics of the settlement and belonging to the present by using today's technological possibilities.

\section{Current state}

The history of Birgi settlement, which was established on the outskirts of Bozdağ in the Odemis district of Izmir province, is based on the Phrygian period in the sources. Afterwards, the settlement (Ocakli Iseri, 1998), which was understood to have continued uninterrupted settlement throughout the Lydian, Persian, Hellenic, Roman, Byzantine, Aydınoglu Principality and Ottoman periods, was named Dioshieron, Pyrgion and Pyrgi in history. Birgi, which was first known as its name known today during the Aydınoğlu Principality period, came to the fore with being the central city of the principality at that time. During the Ottoman period, it gained importance in terms of religion due to the Islamic scholar Imam-i Birgivi, who was known to live in the settlement (Diri, 2010). According to Gumusoglu (2008), the settlement continued to develop until the 17th century, the natural disasters that followed, the rise of Odemis after the Izmir-Aydin railway was built in the 19th century and the changing life culture in the 20th century entered. Today, with this multi-layered historical background and its unique urban and architectural texture, it is experiencing a cultural tourism-driven dynamism. In this context, it can be observed that the historical houses in the centre of the settlement have hosted and breakfast-oriented functional transformations. Although mobility in the form of daily or weekend stays provides economic and cultural improvements in the settlement, it is understood that the local population is insufficient, especially for the young segment, and the trend towards leaving the settlement continues (Sacan, Yilmaz \& Birol, 2019). The fact that the employers are not from the local people in the hostel establishments is an important detail that can be associated with the inability to find sufficient reflection in the public. 


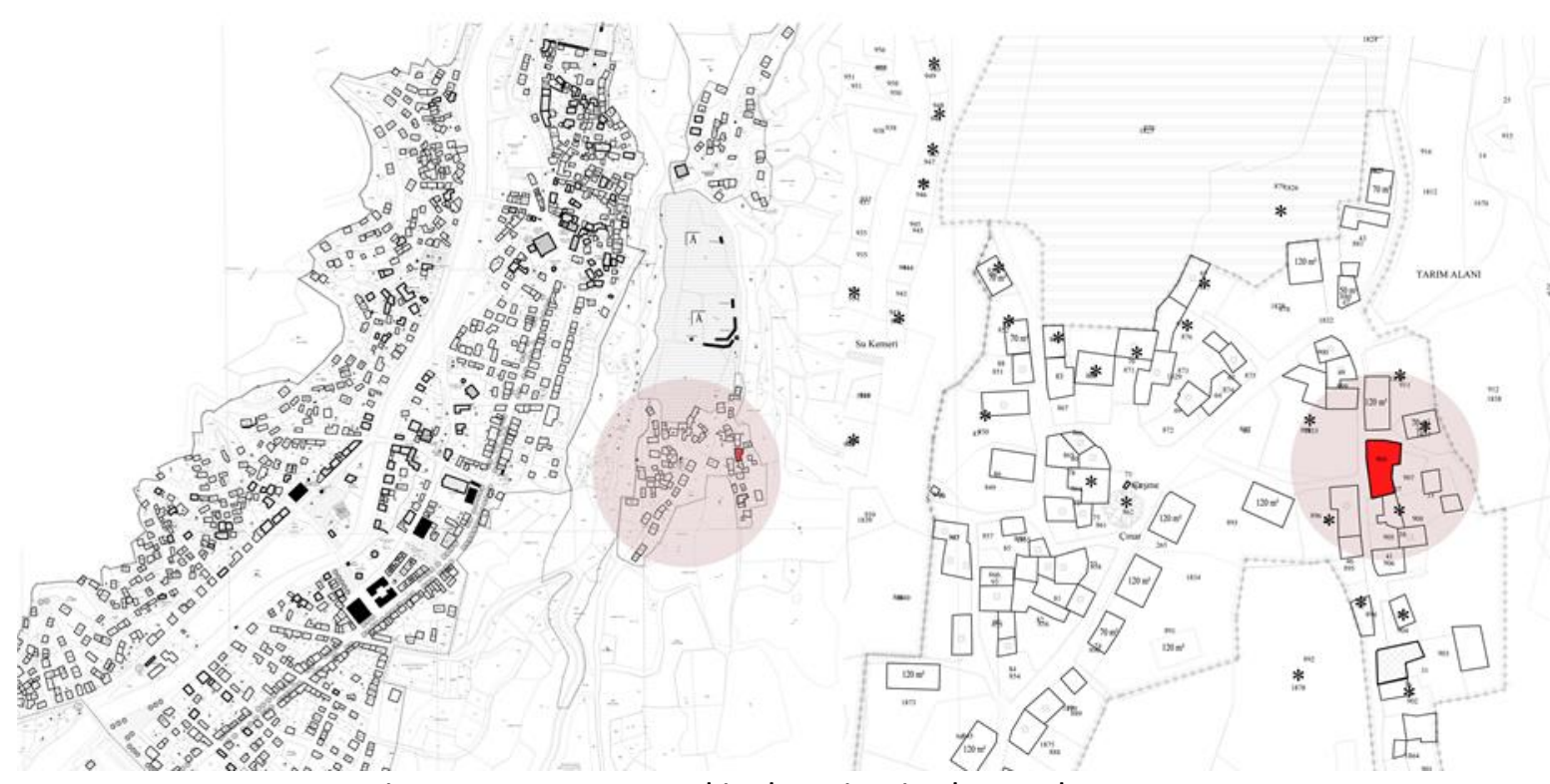

Figure 1. Taspazar and its location in the study area

Taspazar locality, where the structure subject to the study is located, is a low-density residential area located on the outer periphery of Birgi, surrounded by natural landscape. However, the economic difficulties and lack of education opportunities in the process caused the local users to leave the region. For this reason, today's building stock of the area consists of traditional residences that are still in use and buildings that have lost their users and become abandoned and physically worn out. On the other hand, the dynamism experienced in the centre of Birgi also affected the region and the street improvement studies started in 2016. In this context, simple repairs and street-scale improvements were made in the buildings in the Taşpazar area. After the studies, it is observed that the commercial and cultural dynamism in the centre shifted to Taşpazar and ownership change started in some buildings.

While the local users of the region are daily and seasonal producers in Birgi (Gumusoglu, 2008), it is seen that new users continue activities serving tourism and plan to transform the structures they own in this direction. At this point, the renovation methods of the buildings waiting for intervention and the design approaches of the finishing applications in the texture have become an important topic of discussion. The structure in 909 parcels considered within the scope of the study is a good example for discussion, as it has lost its historical integrity, although it partially preserves its original qualities.

The building plot is located at the intersection of two streets, in a location that gives a view to the village square with a fireplace for common use. The building, which has lost its body walls to a great extent, looks like a ruin due to the loss of its mass integrity. Although the data regarding the original architectural setup of the building, documentation studies dated 2006 and the date of its creation are unknown, it was created based on the illustration drawing (Metin Keskin) that reflects the holistic condition of the building. In addition, with the observations and determinations made on the wall, which was able to preserve its integrity in the north direction, concrete data were obtained regarding the location of the building inside the plot, its original use and architectural setup. Thanks to the wall built in the local rubble stone technique and the chimney positioned on it, the height of the building could be

read. The stove at the upper level, two windows at different levels and plaster remains were determined for the number of floors and the distribution of functions. 


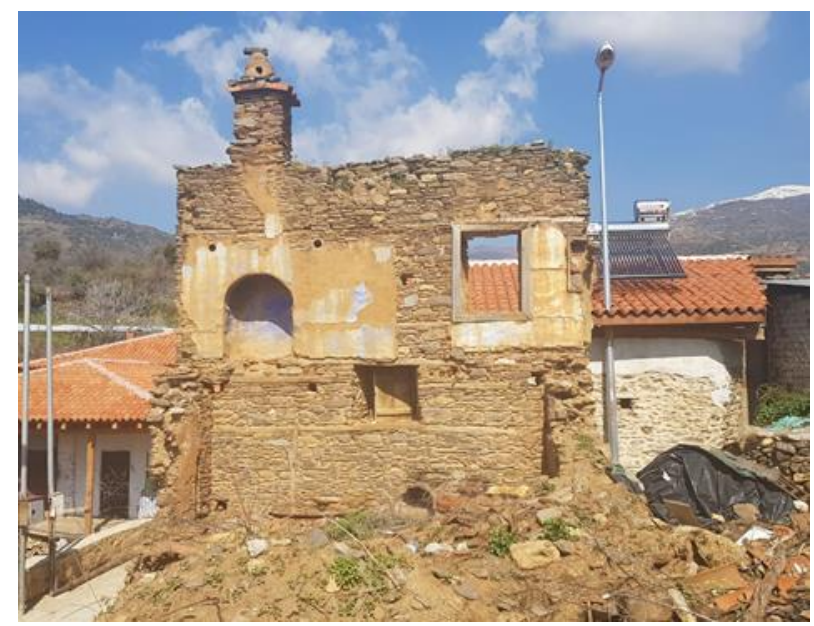

Figure 2. General view of the building, 2019

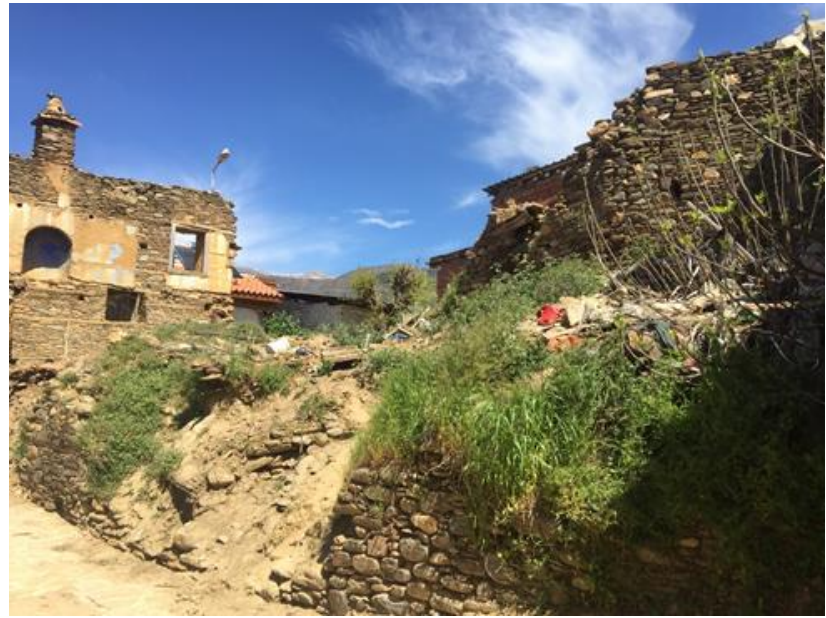

Figure 3. North wall from which chimney, stove and windows can be viewed, 2019

\section{Design approach}

After the determinations, reaching limited data about the original characteristics of the building has provided an experiential design environment that allows new searches and interpretations in the aim of continuing the use and integrating with the architectural language of the texture. In this direction, in order to reflect the temporal losses of the building, the preservation of the existing ruined landscape, the harmony of the new volumes required by the proposed programme with the texture, the reinterpretation of the material culture and the production of all these goals with contemporary architectural understanding and contemporary approaches have been determined as basic design principles.

\subsection{Priority decisions taken in line with the determined approach}

The original function of the building has been to be updated in line with the current needs and demands of the region. In this way, it is aimed to ensure the continuity of the texture by maintaining the traditional residential use and to strengthen the use value of the building with the additional programme. Considering the recent change in the user profile in the region, residential use has been defined over the artist profile due to its potential to adapt and develop the sociocultural structure of the 
location. The function-oriented programme is designed as a workshop, dining area, living area and sleeping area. When the traditional residential life in the surrounding is examined, the importance and widespread use of open and semi-open spaces has been determined and in this direction, the programme setup has been expanded with the needs of terraces and gardens. Another important result of the field studies and literature reviews on the traditional Birgi residential texture and Turkish house has been the presence of more than one function in a single volume (Bektas, 2018). In the design, it is aimed to interpret this spatial practice with the use of modern open plan. The existing original wall remains formed the spatial boundaries, and the continuation of the use of the hearth determined the position of the sitting area. Another design decision was to maintain the material culture and building tectonics. Wooden beams within the characteristic stone structure of the building and garden walls were interpreted as wooden sunshades. With a similar approach, the geometry of the broken roofs, which draws attention in the architectural pattern, was taken as a basis in the shaping of the building shell.

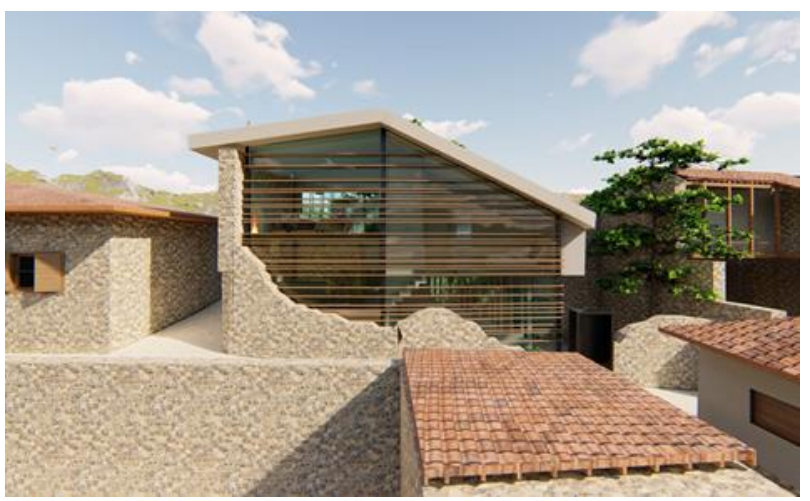

Figure 4. The west facade of the building
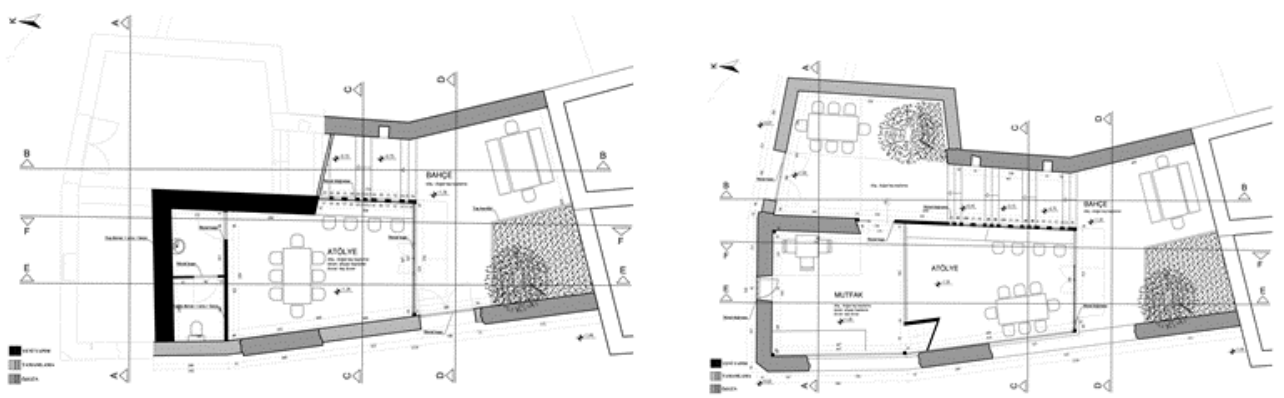

Figure 5. Level plan with the entrance to the workshop 


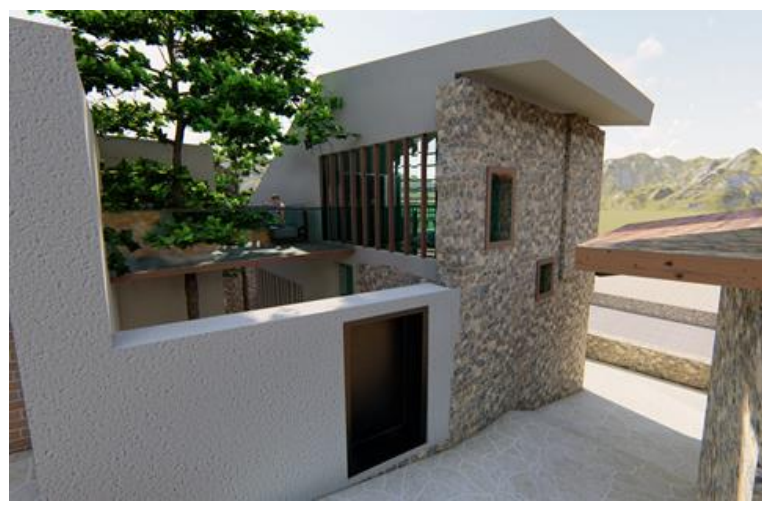

Figure 6. North direction entrance

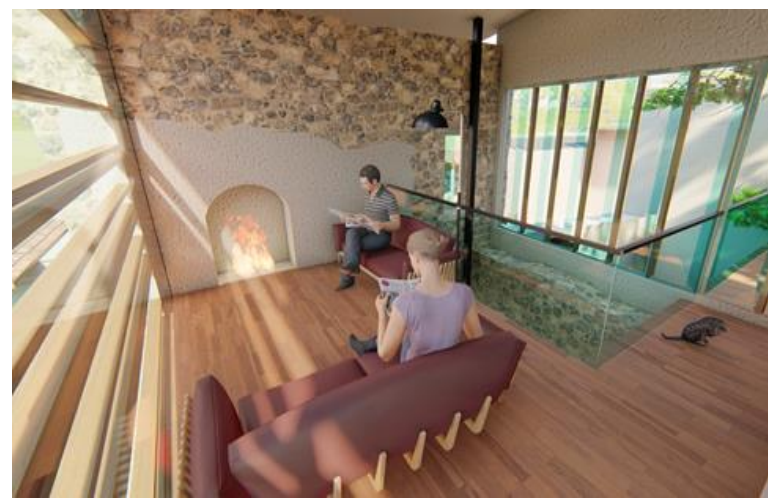

Figure 8. Living area

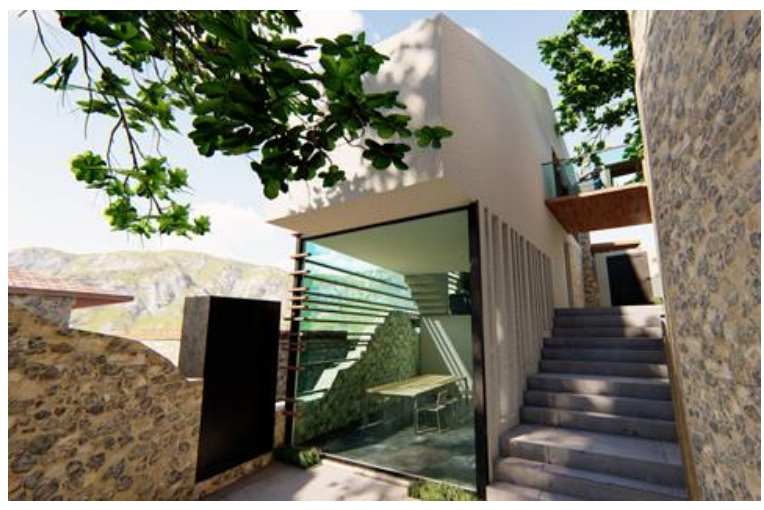

Figure 7. View of the workshop volume from the garden

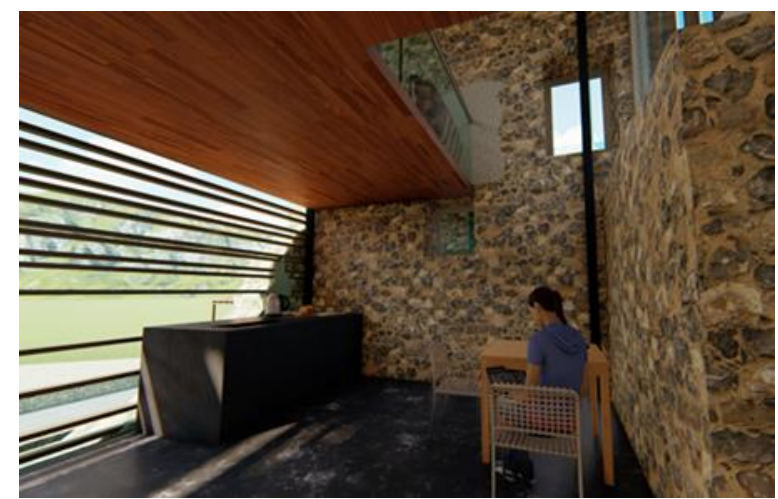

Figure 9. Dining area

The entrance is taken from two streets at different elevations to the building located on the corner parcel. From the square located to the west of the plot, the front of the workshop is reached, and from the street to the north, the rock garden provides access to the house. The spatial levelling required by the programme was achieved by reflecting the elevation differences of the entrance streets into the parcel. The primary goal in the spatial setting is to separate the individual use of the artist and the workshop volume, where he will meet with the local people, with the use of elevations. On the other hand, the visual relationship of the aforementioned uses was achieved with the glass walls created in the interior. The workshop volume opens to the lower garden with the transparent surface on the south facade, and establishes a visual relationship with the stony through the vertical tears on the east facade. Housing life shaped by an open plan consists of living, dining and sleeping areas separated by levelling. The priority of continuing the use of the original furnace and the search for the specialisation of the lying area shaped the volumetric relationships of the functions. By entering the residence from the stony floor at the top level, one reaches the dining area, which creates a visual relationship with the workshop. The sleeping area, which is accessed by the steps rising from the dining area, becomes special with its closed volume leading to the lower garden and emphasises the transparency of the workshop opening to the garden. The wet area serving the residence organises the space as a dividing element between the living area and the sleeping area. The last steps rising from the sleeping area reach the living area. This area is shaped in the focus of the use of the quarry and opens to a terrace overlooking the stony in the east direction. The space that connects the living and dining area sitting on different elevations in the third dimension, on the one hand, strengthens the lower level of light reception, and on the other hand, it ensures that the original body wall is perceived as a whole from all the spaces of the building. 
In the intervention decisions developed within the scope of the restoration works, partial completion was recommended in the parts where structural problems were experienced on the original body walls. Glass and steel were preferred as contemporary materials and systems in the new volumes to be added. In this way, it is aimed to emphasise the original texture and to combine today's technologies with traditional techniques and productions. It is aimed to carry the building designed for the residence/workshop function with a steel structure system placed inside the original body walls, so that the existing walls are not loaded. In addition, the original walls are connected to the steel system at certain intervals and are structurally supported. In the design of the upper crust of the building, it was aimed to protect it from physical effects with the eaves formed in the north and west directions. The transparent western façade of the building gave the opportunity to watch the square and the traditional texture from the interior, and the wooden sunshades used to provide privacy and air conditioning became a means of harmony with the traditional texture.

\section{Evaluation}

Within the scope of the study, which includes a completion trial in the traditional settlement of Birgi, Taşpazar, it is envisaged that a traditional building, which has lost its historical integrity, will be completed with a contemporary approach by maintaining its original architectural and functional values. In the work carried out, the existence of the traditional texture with a contemporary language was discussed, and the possibilities of the characteristic features of the place to shape the architectural design were examined. The experience that has been carried out highlights two issues to be considered in new building designs in traditional textures. They are to prioritise local life practices in determining the new function and programme, and the interpretation of traditional characteristics with a contemporary language.

It is important to develop suggestions that are compatible with the local life practices and current dynamics of the area that will strengthen the socio-economic environment of the region in determining the new use that will be articulated to traditional textures. These proposals are expected to include programmes that maintain traditional spatial practices and meet the needs of contemporary life.

Completion and renovation work to be carried out in traditional textures should be produced by assimilating the subjective characteristics of the field and interpreting it with the knowledge and technology of the day. These productions require an expert perspective that can define the cultural values of traditional tissues and the factors that should be prioritised in intervention decisions. This view offers the opportunity to produce designs that interpret the urban and architectural characteristics of the place with a day-to-day look, instead of producing imitations of the present. With this approach, it will be possible to make the interventions belong to the day and to emphasise the uniqueness value of the traditional texture.

\section{References}

Archive of Y. Architect Guzide Budun. 2006 dated survey study.

Birol Akkurt, H. (2010). Sustainability in Architectural Conservation Discipline; Goals, Possibilities. In N. Ozaslan \& D. Ozkut (Eds.), Current issues in architectural conservation (pp. 154-171). Eskisehir, Turkey: Anadolu University Press. 
Birol Akkurt, H., Ozkaban, F. \& Dokgoz, D. (2016). Contemporary building design in historical texture: borders, possibilities. 4th Environmental Design Congress, Kayseri, 5-6 May 2016.

Bektas, C. (2018). Istanbul, Turkey: Turkish House, Yem Publication.

Gumusoglu, F. (2008). Social Life and Change in Birgi. Istanbul, Turkey: Baglam Publications.

Karakul, O. (2009). New building in the historical environment in the triangle of change, continuity, harmony. UCTEA Chamber of Architects Ankara Branch File Magazine, 14, 50-57.

Birgi, the city that protects itself (brochure). (2018). Istanbul, Turkey: CEKUL Foundation.

Ocakli Iseri, K. (1998). Birgi is a study of the city and architecture (Unpublished master's thesis). Marmara University Turkic Studies Institute, Istanbul.

Semes, S. W. (2007). Differientated and compatiable: four strategies for additions to historic settings. In Sense of place: design guidelines for new construction in historic districts (pp. 4-11). Philadelphia, PA: William Penn Foundation.

Sacan, C., Yilmaz, Y. \& Birol, H. (2019). The role of place identity in the preservation of Birgi historical settlement with a sustainable approach. IBAD Journal of Social Sciences, 185-197. 